\title{
Alimentação escolar e a agricultura familiar: um enfoque no desenvolvimento local
}

\author{
Reinaldo Knorek ${ }^{1}$ \\ Jairo Marchesan ${ }^{2}$ \\ Edenir Assis Leite de Paula Rocha ${ }^{3}$ \\ Terezinha de Fátima Juraczky Scziminski ${ }^{4}$ \\ Jonas Fábio Maciel $^{5}$
}

\begin{abstract}
Resumo
Investiga-se a relação entre a Política Nacional de Alimentação Escolar (PNAE) e a agricultura familiar, nos municípios de Major Vieira e Canoinhas, localizados no Planalto Norte Catarinense. $\mathrm{O}$ artigo 14 da Lei $\mathrm{n}^{\circ}$ 11.947, de 16 de junho de 2009, determina que 30\% do total de recursos financeiros repassados pelo Fundo Nacional de Desenvolvimento da Educação (FNDE) devem ser utilizados na aquisição de gêneros alimentícios provenientes da agricultura familiar do município ou região aos quais a escola pública pertence. Este Programa tem como um dos objetivos a contribuição para com o desenvolvimento econômico e social da região, por meio do estímulo à produção e comercialização de produtos locais. As argumentações analisam os dados de quatro anos e meio da instituição do programa nos referidos municípios.
\end{abstract}

Palavras-chave: Alimentação escolar. Agricultura familiar. Desenvolvimento local.

\begin{abstract}
Investigates the relationship between the National School Nutrition Policy (PNAE) and family farming in the municipalities of Major Vieira and Canoinhas, located in North Santa Catarina Plateau. Article 14 of Law No. 11.947, of June 16, 2009, states that 30\% of the total funds transferred by the National Fund for Education Development (ENDF) should be used in the purchase of food from family farms in the municipality or region in which the public school belongs. This program has a contribution to economic and social development of the region by stimulating the production and marketing of local products as one of the goals. The arguments analyze data from four and a half years of the institution of the program in those counties.
\end{abstract}

Keywords: School feeding. Family agriculture. Local development.

\footnotetext{
${ }^{1}$ Doutor em Engenharia de Produção. Professor do Programa de Mestrado em Desenvolvimento Regional - UnC. CAPES - Orientador: Projeto Pro Integração, Edital 55/2013. reinaldoK@unc.br

${ }^{2}$ Doutor em Geografia. Professor do Programa de Mestrado em Desenvolvimento Regional - UnC. jairo@unc.br.

3 Mestrando em Desenvolvimento Regional -UnC. Bolsista CAPES - Projeto Pro Integração, Edital 55/2013. Bolsista CAPES - Projeto Pro Integração, Edital 55/2013. edenir@unc.br

${ }^{4}$ Mestranda em Desenvolvimento Regional - UnC. Bolsista CAPES - Projeto Pro Integração, Edital 55/2013.Terezinha@unc.br

${ }^{5}$ Mestrando em Desenvolvimento Regional - UnC. Bolsista CAPES - Projeto Pro Integração, Edital 55/2013. jonasfmaciel@hotmail.com.
} 


\section{Introdução}

Conforme o Programa Nacional de Alimentação Escolar (PNAE), criado em 1954 pelo Ministério da Saúde e formalizada em 1955, no Ministério da Educação e Cultura, por meio do decreto $n$ o 37.106/55, a alimentação escolar tem como objetivo principal a redução da desnutrição das crianças que frequentam as escolas, bem como a melhoria de seus hábitos alimentares.

A partir da década de 1960, ocorreram diversas alterações na política de transferência de recursos destinados à alimentação dos alunos da rede pública de ensino, todas com o objetivo de complementar a alimentação e, consequentemente, dignificar a qualidade de vida desses alunos.

Uma destas alterações, argumento-chave deste artigo, possui foco na perspectiva do desenvolvimento local. De acordo com o Fundo Nacional de Desenvolvimento da Educação, conforme o artigo 14 da Lei $n^{\circ}$ 11.947, de 16 de junho de 2009, do total de recursos financeiros repassados pelo Fundo Nacional de Desenvolvimento da Educação (FNDE), no âmbito do PNAE, no mínimo 30\% devem ser utilizados na aquisição de gêneros alimentícios provenientes da agricultura familiar.

Desta política de transferência, ocorreu a adequação da alimentação dos alunos às peculiaridades e características regionais, bem como uma maior agilidade no processo de aquisição da merenda ${ }^{6}$, e, assim, uma possível forma de desenvolvimento regional.

Convencionalmente, o agricultor familiar (individual ou cooperado), possivelmente, não teria condições de competir em licitações com médias e grandes empresas, para o fornecimento de produtos destinados à alimentação escolar. Com a obrigatoriedade determinada pela legislação, oportuniza-se aos pequenos produtores a alternativa de atender às demandas. Assim, estimula-se a permanência do agricultor no campo, a melhoria de vida de sua família e o desenvolvimento econômico e social da região.

Com esta realidade, o argumento central desta reflexão objetiva uma análise sobre a contribuição da referida política nacional, para o desenvolvimento local, por meio dos repasses realizados aos municípios catarinenses de Major Vieira e Canoinhas.

O referencial teórico aponta as evoluções legais do direito à alimentação escolar; concepções sobre a agricultura familiar e bases teóricas sobre o desenvolvimento local, além do levantamento de informações referentes aos repasses do programa aos municípios citados.

\section{Programa Nacional de Alimentação Escolar - PNAE}

A alimentação escolar, no Brasil, chamada de merenda escolar, tem sua origem na iniciativa privada, seguida por um Programa coordenado pelo Governo Federal. A iniciativa ocorreu pela preocupação em relação à desnutrição infantil.

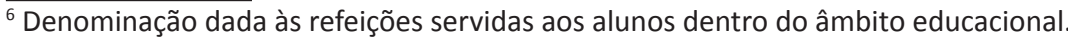


As políticas e programas de alimentação e nutrição no Brasil tiveram início na década de 1930, quando ficou definido que o alimento essencial deveria ser um dos itens garantidos pelo salário mínimo (instituído em 1940). No entanto, o salário mínimo não era suficiente para fornecer uma alimentação adequada para os trabalhadores. Esta situação levou à criação, em 1940, do Serviço de Alimentação e Previdência Social (SAPS) cujos objetivos principais eram baratear o preço dos alimentos, criarem restaurantes para os trabalhadores e fazer com que as empresas fornecessem alimentos para seus trabalhadores em seus próprios refeitórios (BRASIL, 2014).

Segundo o caderno de estudos sobre a alimentação e nutrição no Brasil (2007), em 1945, criou-se a Comissão Nacional de Alimentação (CNA). Essa comissão objetivava estudar e propor normas para a política nacional de alimentação. Em 1952, a Comissão estabeleceu o Plano Nacional de Alimentação, que teve como escopo de trabalho a atenção à nutrição materna, a criação do programa da Merenda Escolar e a assistência ao trabalhador. Esse plano considerava a desnutrição o maior problema de saúde pública do país, devido ao impacto nacional desta problemática, porém as ações do plano não trabalhavam de forma incisiva a causa da desnutrição.

Em 1954, foi criado o PNAE pelo Ministério da Saúde, formalizado em 1955, no Ministério da Educação e Cultura, por meio do decreto nㅇ 37.106/55, tendo como objetivos principais a redução da desnutrição das crianças, bem como a melhoria dos hábitos alimentares.

Com a constituição de 1988, o Programa da Alimentação Escolar (Suplementação), ganhou um caráter universal com a Carta Cidadã, tendo princípios norteadores, como as necessidades nutricionais dos alunos.

De 1993 a 1996, o governo comprometeu-se a combater a fome. Em 1993, publicou-se o Mapa da Fome, trazendo informações que auxiliaram na elaboração inicial de uma Política de Segurança Alimentar. Esse mapa identificou a existência de 32 milhões de indigentes no país.

A partir de 1993, ocorreu um grande movimento organizado pela sociedade civil, ou seja, pessoas sem vínculo com o governo. O movimento foi liderado pelo sociólogo Herbert de Souza, o Betinho, e se chamava 'Ação da Cidadania Contra a Fome, a Miséria e Pela Vida' (BRASIL, 2014, p. 37).

Em 1993, criou-se o Conselho Nacional de Segurança Alimentar (CONSEA), o qual elaborou um Plano de Combate à Fome e à Miséria, tendo como prioridade a geração de emprego e renda, a democratização da terra, o combate à desnutrição materno-infantil, a descentralização e o fortalecimento do PNAE.

Em 1994, criou-se a Lei no 8.913/1994, definindo a descentralização do PNAE. Isso significa dizer que os municípios, estados e o Distrito Federal passaram a ter a responsabilidade de planejar os cardápios, comprar e analisar a qualidade dos alimentos e distribuí-los em seus territórios. Com isso, adequou-se a alimentação escolar a cada região, de acordo com sua cultura e necessidade.

Foi na década de 90 que as políticas públicas relacionadas à alimentação escolar foram pensadas em âmbitos municipal e intermunicipal. Nessa década, houve a formulação de uma política de desenvolvimento local, na qual destacou-se a importância da Agricultura Familiar. A produção familiar responde por $38 \%$ do valor bruto da produção 
agropecuária nacional e ocupa $77 \%$ da mão de obra do campo (BRASIL, 2006).

Em 2003, o CONSEA foi reativado com o nome de Conselho Nacional de Segurança Alimentar e Nutricional. Em 2003, criou-se o Programa Fome Zero, como uma estratégia do Governo Federal para erradicar a fome no Brasil. Este programa é composto por um conjunto de ações e estratégias e colocado em execução pelos seguintes Ministérios: Desenvolvimento Social e Combate à Fome; Desenvolvimento Agrário; Saúde; Educação, Agricultura, Pecuária e Abastecimento, Trabalho e Emprego, Integração Nacional, Fazenda e Planejamento.

O Programa visava a quatro tipos de enfoques diferentes: ampliação do acesso aos alimentos; fortalecimento da agricultura familiar; geração de renda; articulação, mobilização e controle social. A partir desse cenário, considerando a vinculação histórica do Programa Nacional de Alimentação Escolar e visando apoiar a agricultura familiar, houve a necessidade de aprimoramento dos mecanismos de Desenvolvimento Local e Territorial, que até então esteve à margem das políticas públicas setoriais.

A partir de sancionada a Lei no 11.947, em 16 de junho de 2009, e por meio da Resolução FNDE no 38, e o artigo 6으 da Resolução do FNDE, no 26/2013, os estados poderiam transferir a seus municípios a responsabilidade pelo atendimento aos alunos matriculados nos estabelecimentos estaduais de ensino localizados nas respectivas áreas de jurisdição e, nesse caso, autorizar diretamente ao município o repasse de recursos do FNDE referentes a esses estudantes.

De acordo com o Fundo Nacional de Desenvolvimento da Educação, conforme o artigo 14 da Lei $n^{\circ} 11.947$, de 16 de junho de 2009, do total de recursos financeiros repassados pelo FNDE, no âmbito do PNAE, no mínimo $30 \%$ devem ser utilizados na aquisição de gêneros alimentícios provenientes diretamente da agricultura familiar e do empreendedor familiar rural ou de suas organizações. Portanto, a aquisição é obrigatória. Segundo o artigo 24, §1으, da Resolução CD/FNDE no 26, de 17 de junho de 2013, a aquisição pode ser realizada com a dispensa do procedimento licitatório, desde que os preços sejam compatíveis com os vigentes no mercado local, observando-se os princípios inscritos no art. 37 da Constituição Federal, e que os alimentos atendam às exigências do controle de qualidade estabelecidas pelas normas que regulamentam a matéria. No caso de dispensa do procedimento licitatório, a aquisição deverá ser realizada por meio de chamada pública, procedimento regulamentado pelo normativo do PNAE.

\section{Concepções sobre agricultura familiar}

A agricultura familiar é um termo utilizado para denominar um modelo de organização produtiva rural, normalmente minifúndio e de trabalho familiar. Com isso, o agricultor familiar é o integrante deste grupo, o principal proprietário dos meios de produção (terra e mão de obra) e trabalha de forma não assalariada e mais cooperativa, sendo o lucro das atividades desenvolvidas na propriedade a fonte de renda dos integrantes da família.

De acordo com a Lei no 11.326/2006, publicada no Diário Oficial da União, em 24 de julho de 2006 (BRASIL, 2006), considera-se agricultor familiar aquele que pratica atividades no meio rural, possui área de até quatro módulos fiscais, mão de obra familiar, 
renda vinculada ao próprio estabelecimento, cujo gerenciamento ou empreendimento é feito pela própria família. Também são considerados agricultores familiares silvicultores, aquicultores, extrativistas, pescadores, indígenas, quilombolas e assentados da reforma agrária.

De acordo com o Manual do Programa Nacional de Alimentação Escolar - PNAE (2014), o agricultor familiar é reconhecido pelo Ministério do Desenvolvimento Agrário por meio da Declaração de Aptidão ao PRONAF (DAP). Este documento é o instrumento de identificação do agricultor familiar, utilizado para o acesso às políticas públicas. A DAP pode ser de pessoa física, destinada a identificar o produtor individual e sua família, ou jurídica. A DAP jurídica é o instrumento que identifica as formas associativas dos agricultores familiares, organizados em pessoas jurídicas devidamente formalizadas.

\section{A agricultura familiar e o desenvolvimento local}

Ao se propor o desenvolvimento local como objetivo de um programa nacional que se utiliza de transferência de recursos, faz-se necessário entender quais concepções de desenvolvimento estão em jogo. O desenvolvimento possui diversas conceituações e interpretações.

Como a discussão gira em torno do desenvolvimento econômico e social de uma determinada região, por meio de uma política de incentivo ao agricultor familiar, faz-se pertinente utilizar concepções de autores como Boisier (2010, p. 34), que clarificam uma linha conceitual generalista sobre o tema:

Desarrollo es una propiedad emergente de un sistema territorial complejo dependiente de la historia y del territorio, que genera las condiciones de entorno (una matriz urbana sin primacía excesiva, una matriz productiva con incorporación de progreso técnico, una matriz social bien dotada de capital social y cohesionada, una matriz política con elevado capital cívico, una matriz científica y tecnológica audaz, una matriz ecológica que genere sustentabilidad, y una matriz cultural generadora de identidad) condiciones éstas que permiten a los individuos alcanzar la categoría de personas humanas y constituir una comunidad y una sociedad territorial, o región.

Analisam-se, em Boisier, algumas concepções que comungam com o ideal de agricultura familiar definida pelo PNAE. Quando o autor trata o desenvolvimento como uma propriedade que depende de fatores históricos e culturais que geram identidade à região, verifica-se como característica da agricultura familiar um enraizamento local, sendo que uma das principais características desta unidade é o trabalho na terra da família, sendo esta passada para as gerações futuras, assim como o conhecimento sobre as diversas atividades produtivas realizadas nas propriedades.

A concepção prática de desenvolvimento utilizada pelo governo federal em seu FNDE é tratada pela Lei no 11.947/2009 (BRASIL, 2009), que dispõe sobre o atendimento à alimentação escolar, em especial no que tange ao artigo $2^{\circ}$, publicado no Diário Oficial da União, considerando como um dos objetivos do programa: 
Ao emprego da alimentação saudável e adequada, compreendendo o uso de alimentos variados, seguros, que respeitem a cultura, as tradições e os hábitos alimentares saudáveis (Art. 2ㅇ; §I).

O apoio ao desenvolvimento sustentável, com incentivos para a aquisição de gêneros alimentícios diversificados, produzidos em âmbito local e preferencialmente pela agricultura familiar e pelos empreendedores familiares rurais, priorizando as comunidades tradicionais indígenas e de remanescentes de quilombos (Art. 2o; § V).

Está intrínseco na Lei no 11.947/2009 (BRASIL, 2009) o entendimento sobre desenvolvimento de uma região utilizando concepções de desenvolvimento endógeno ${ }^{7}$. Esta considera importante a preferência, no consumo, de produtos locais, por questões de preservação do fluxo de recursos, além de uma visão de inclusão social, ao privilegiar as organizações produtivas mais vulneráveis e de baixa competitividade, na lei citada como agricultores familiares, comunidades indígenas e quilombolas. Inerente a esta conceituação, observa-se no Programa a mesma argumentação presente em Boisier na elaboração de uma visão de desenvolvimento. No § I do artigo $2^{\circ}$, determina-se que os gêneros alimentícios devem respeitar a cultura e as tradições. Entende-se que, dessa forma, o Programa estaria preservando as características sociais locais, atitude importante, considerando as agudas diferenças culturais presentes no Brasil.

Com base na Lei no 11.947/2009, o FNDE (BRASIL, 2014) determina, em suas políticas de trabalho, que o apoio ao desenvolvimento sustentável ${ }^{8}$ local ocorre pela priorização da compra de produtos diversificados, orgânicos ou agroecológicos. Tendo este foco ambiental e social, o FNDE afirma, em seu site oficial, que toda a PNAE significa geração de emprego e renda, fortalecendo e diversificando a economia local, e valorizando as especificidades e os hábitos alimentares locais.

\section{Repasses do FNDE}

O Programa é executado por entidades que recebem diretamente os recursos do FNDE para a operação do PNAE. As entidades executoras que o recebem diretamente são as instituições da rede pública de ensino federal, estadual e municipal. Segundo o Manual do PNAE (2014), estas entidades são Secretarias Estaduais de Educação, Prefeituras e Escolas federais.

Em relação ao percentual destinado à comercialização de produtos oriundos da agricultura familiar (30\%), o mesmo só pode ser utilizado quando o agricultor se enquadra na seguinte classificação:

\footnotetext{
${ }^{7}$ Para compreender o conceito, consultar Desarrollo endógeno. Teorías y políticas de desarrollo territorial, de Antonio Vázquez Barquero.

${ }^{8}$ Entendendo como desenvolvimento sustentável um equilíbrio entre as três esferas do Desenvolvimento Regional: econômica, social e ambiental.
} 
- Grupos formais: detentores de Declaração de Aptidão ao Pronaf (DAP jurídica) - cooperativas e associações de agricultores familiares devidamente formalizadas;

- Grupos informais: grupos de agricultores familiares detentores de Declaração de Aptidão ao Pronaf (DAP física), que se articula para apresentar o projeto de venda;

- Fornecedores individuais: agricultores familiares detentores de Declaração de Aptidão ao Pronaf (DAP física). (MANUAL PNAE, 2014, p. 7).

Respeitadas as premissas descritas anteriormente, executa-se o processo para a aquisição de produtos de agricultores familiares.

\section{Quadro 1 - Processo de aquisição de produtos pelo PNAE}

1o - ORÇAMENTO: levantamento dos recursos orçamentários disponíveis

2o - ARTICULAÇÃO ENTRE OS ATORES SOCIAIS: mapeamento dos produtos da agricultura familiar

3- - CARDÁPIO

4 - PESQUISA DE PREÇO

5- - CHAMADA PÚBLICA

6 ○ - ELABORAÇÃO DO PROJETO DE VENDA

7ํ - RECEBIMENTO E SELEÇÃO DOS PROJETOS DE VENDA

8ㅇ - AMOSTRA PARA CONTROLE DE QUALIDADE

9o - CONTRATO DE COMPRA

10 - ENTREGA DOS PRODUTOS, TERMO DE RECEBIMENTO E PAGAMENTO DOS AGRICULTORES

Fonte: Manual PNAE (2014).

Desde 1995, são realizados repasses do FNDE para as entidades executoras do PNAE. No site do FNDE (BRASIL, 2014), é possível verificar o total de repasses às entidades, assim como o total de alunos atendidos. 
Quadro 2 - Dados referentes aos repasses e alunos atendidos pelo FNDE

\begin{tabular}{|c|c|c|}
\hline Ano & $\begin{array}{c}\text { Recursos financeiros } \\
\text { (em R\$ milhões) }\end{array}$ & $\begin{array}{c}\text { Alunos atendidos } \\
\text { (em milhões de alunos) }\end{array}$ \\
\hline 1995 & 590,1 & 33,2 \\
\hline 1996 & 454,1 & 30,5 \\
\hline 1997 & 672,8 & 35,1 \\
\hline 1998 & 785,3 & 35,3 \\
\hline 1999 & 871,7 & 36,9 \\
\hline 2000 & 901,7 & 37,1 \\
\hline 2001 & 920,2 & 37,1 \\
\hline 2002 & 848,6 & 36,9 \\
\hline 2003 & 954,2 & 37,3 \\
\hline 2004 & 1.025 & 37,8 \\
\hline 2005 & 1.266 & 36,4 \\
\hline 2006 & 1.500 & 36,3 \\
\hline 2007 & 1.520 & 35,7 \\
\hline 2008 & 1.490 & 34,6 \\
\hline 2009 & 2.013 & 47,0 \\
\hline 2010 & 3.034 & 45,6 \\
\hline 2011 & 3.051 & 44,4 \\
\hline 2012 & 3.306 & 43,1 \\
\hline
\end{tabular}

Fonte: Fundo Nacional de Desenvolvimento da Educação (2014).

A partir de 2009, a Lei no 11.947 torna obrigatória a destinação de 30\% destes recursos do FNDE para a aquisição de produtos da agricultura familiar. Segundo a Prefeitura Municipal de Major Vieira (2014), o município recebeu do FNDE, de 2009 a 2013, $\mathrm{R} \$ 256.140,00$. Levantando o percentual utilizado destes recursos na agricultura familiar, tem-se o seguinte quadro:

Quadro 3 - Percentual referente aos repasses do FNDE gasto com produtos da agricultura familiar em Major Vieira

\begin{tabular}{|c|c|}
\hline Ano & Gasto total - em \% \\
\hline 2009 & - \\
\hline 2010 & 16 \\
\hline 2011 & 41 \\
\hline 2012 & 87 \\
\hline 2013 & 76 \\
\hline
\end{tabular}

Fonte: Prefeitura Municipal de Major Vieira (2014). 
Canoinhas, segundo a Prefeitura Municipal do município (2014), foi contemplado com o repasse de R\$2.213.906,00, entre os anos de 2009 e 2013.

Levantando o percentual utilizado destes recursos na agricultura familiar, tem-se o seguinte quadro:

Quadro 4 - Percentual referente aos repasses do FNDE gasto com produtos da agricultura familiar em Canoinhas

\begin{tabular}{|c|c|}
\hline Ano & Gasto total - em \% \\
\hline 2009 & 38,87 \\
\hline 2010 & 38,87 \\
\hline 2011 & 58,48 \\
\hline 2012 & 47,24 \\
\hline 2013 & 60,42 \\
\hline
\end{tabular}

Fonte: Prefeitura Municipal de Canoinhas (2014).

\section{Indicadores socioeconômicos de Major Vieira e Canoinhas}

Faz-se importante analisar alguns dos principais indicadores econômicos, a partir de 2009, dos dois municípios aos quais o PNAE propicia uma movimentação econômica na agricultura familiar por meio dos recursos do FNDE.

\section{Quadro 5 - Indicadores econômicos}

\begin{tabular}{|l|c|c|}
\hline Indicador/ Cidade & Major Vieira & Canoinhas \\
\hline PIB2009-2011 & $\mathrm{R} \$ 353,6$ milhões & $\mathrm{R} \$ 2.785,9$ milhões \\
\hline PIB per CAPITA* & $\mathrm{R} \$ 15,7$ mil & $\mathrm{R} \$ 17,6$ mil \\
\hline
\end{tabular}

Fonte: Instituto Brasileiro de Geografia e Estatística (2014).

*Média dos anos de 2009 a 2010, baseado no Censo 2010.

Em relação aos indicadores da educação dos dois municípios, destacam-se:

\section{Quadro 6 - Indicadores da Educação}

\begin{tabular}{|l|c|c|}
\hline Indicador/ Cidade & Major Vieira & Canoinhas \\
\hline Analfabetismo 11-14 anos - 2010 & 0,86 & 1,26 \\
\hline IDEB 2011 & $5,0^{*}$ & $5,9 * *$ \\
\hline
\end{tabular}

Fonte: Atlas do Desenvolvimento (2014); BRASIL (2014).

* Meta do município 4,5

** Meta do município 5,5 


\section{Considerações finais}

Proporcionalmente em relação ao PIB de 2009 a 2012, os repasses geraram praticamente o mesmo impacto na economia dos dois municípios. Quanto aos indicadores da educação, verifica-se a presença de analfabetismo, apesar do IDEB de ambos os municípios ter superado a meta para 2011.

Partindo do referencial e da pesquisa realizada, a agricultura familiar pode auxiliar na geração de identidade à região, quando esta oferece produtos regionais às crianças e adolescentes, porém deve-se considerar que há outras argumentações teóricas sobre o desenvolvimento local e regional, as quais merecem atenção. No artigo, a preocupação não foi debater sobre as diversas linhas, e, sim, utilizar-se de uma linha que coincidisse com alguns dos objetivos do PNAE, além de colocar em evidência as lacunas deixadas pelo programa no que tange ao desenvolvimento regional.

Na relação entre alimentação escolar e agricultura familiar, analisou-se PNAE, o qual prevê, desde 2009, repasses de recursos diretamente do FNDE, para a melhoria da alimentação escolar da rede pública de ensino. Este programa possui como um dos objetivos a contribuição ao desenvolvimento econômico e social regional, sendo este ponto o motivador para a busca de dados que demonstrassem, na realidade, o quanto os municípios de Major Vieira e Canoinhas seriam impactados social e economicamente.

De 2009 a 2013, o município de Major Vieira recebeu R\$ 256.140,00, e o município de Canoinhas, $\mathrm{R} \$ 2.213 .906,00$, confirmando, assim, a inclusão destes municípios no PNAE. No primeiro, observou-se que os recursos do FNDE destinados à agricultura familiar foram aplicados no devido fim, respeitando o mínimo de $30 \%$ de gastos com a agricultura familiar a partir de 2011. Com isso, pode-se afirmar que a normalização no uso dos recursos do FNDE, dentro do PNAE, estimulou a comercialização de produtos oriundos da agricultura familiar neste município, algo que não é observado de forma representativa nos anos de 2009 e 2010. Atualmente, a referida prefeitura aplica quase que a totalidade dos recursos disponíveis do FNDE na agricultura familiar.

No município de Canoinhas, é observável como contínua e consistente a aquisição de produtos da agricultura familiar, para a alimentação escolar, verificando que, desde 2009, esse município utiliza mais de $30 \%$ dos recursos do FNDE na aquisição deste tipo de produtos. Há de se considerar que, comparando os dois municípios pesquisados, a agricultura do tipo familiar, em Canoinhas, por ser maior em vários aspectos, possivelmente por oferecer uma gama maior de produtos, oportunizando a negociação com o município, como já fazia antes e sem a obrigatoriedade.

Analisando os dados, considera-se que o impacto dos valores, nos dois municípios, pode contribuir para a movimentação econômica local com relativa importância, podendo auxiliar produtores que não possuem nível de competitividade de mercado. No âmbito nacional, os montantes repassados pelo FNDE são de considerável relevância, atingindo a casa dos $\mathrm{R} \$$ 3,3 bilhões em 2012. Considerando os 30\%, desde 2010 (Lei aprovada em junho de 2009), torna-se uma lógica que nos leva a pensar que, no mínimo, $\mathrm{R} \$ 2,8$ bilhões deveriam movimentar a agricultura familiar brasileira. Ao injetar tais valores em pequenas propriedades, muitos resultados ligados ao desenvolvimento local possivelmente foram alcançados, como a fixação do homem ao meio rural e a melhoria 
na qualidade de vida desses agricultores.

Partindo da consideração do governo federal (já devidamente referenciada): “A PNAE significa geração de emprego e renda, fortalecendo e diversificando a economia local, e valorizando as especificidades e os hábitos alimentares locais", considera-se, de forma a finalizar a argumentação, que o Programa pode contribuir para o desenvolvimento econômico e social, transferindo recursos federais para a comercialização de produtos rurais da agricultura familiar. No campo social do desenvolvimento, pode auxiliar na manutenção dos hábitos e costumes gastronômicos, além da manutenção dos cultivos agrícolas próprios da região, o que também é um fator de identidade local. Isso leva os jovens a manterem contato com algumas das raízes regionais. O que se verifica ao argumentar sobre o Programa é que este não possui caráter de solução à problemática econômica e social local: assumindo, portanto, um papel contributivo.

Em ambos os municípios é pertinente a continuação desta investigação, podendo se levantar informações mais analíticas e empíricas sobre o Programa, além de investigar as aquisições realizadas e verificar se realmente os fornecedores se enquadram na concepção de agricultores do modelo familiar de produção.

\section{Referências}

ATLAS DO DESENVOLVIMENTO. Disponível em: <http://www.atlasbrasil.org.br/2013/>. Acesso em: 23 jul. 2014.

BOISIER, Sergio. Descodificando El desarrollo Del siglo XXI: Subjetividad, complejidad, sinapsis, sinergia, recursividad, liderazgo, y anclaje territorial. Semestre Económico, Medellín, v. 13, n. 27, 2010.

BRASIL. Fundo Nacional de Desenvolvimento da Educação. Disponível em: <http://www.fnde.gov.br/programas/alimentacao-escolar>. Acesso em: 12 jun. 2014.

Lei $n^{\circ}$ 11.947, de 16 de junho de 2009. Diário Oficial da União. Brasília, DF, 2009. Disponível em: <http://www.planalto.gov.br/ccivil_03/_ato2007-2010/2009/lei/ |11947.htm>. Acesso em: 10 jul. 2014.

. Lei no 11.326/2006. Diário Oficial da União. Brasília, DF, 2006. Disponível em: <http://www.planalto.gov.br/ccivil_03/_ato2004-2006/2006/lei/l11326.htm>. Acesso em: 20 jul. 2014.

. Ministério da Educação. Relatório Profunc. Brasília, DF. 2014. Disponível em: <http://portal.mec.gov.br/seb/arquivos/pdf/profunc/aliment.pdf>. Acesso em: 26 maio 2014.

Ministério da Educação. Secretaria de Educação Básica. Alimentação e nutrição no Brasil I. Maria de Lourdes Carlos Rodrigues et al. Brasília: Universidade de Brasília, 2007. Disponível em: <http://portal.mec.gov.br/seb/arquivos/pdf/profunc/ aliment.pdf>. Acesso em: 26 maio 2014. 
- Ministério do Desenvolvimento Agrário. Apresentação - Crédito. Brasília, DF. 2006. Disponível em: <http://www.mda.gov.br/saf/index. php?sccid=811>. Acesso em: 26 maio 2014.

INSTITUTO BRASILEIRO DE GEOGRAFIA E ESTATÍSTICA. IBGE. Senso 2010. Disponível em: <http://www.cidades.ibge.gov.br/xtras/temas.php?lang=\&codmun= 421030\&idte$\mathrm{ma}=1 \&$ search=santa-catarina $\mid$ major-vieira |censo-demografico-2010:-sinopse>. Acesso em: 10 jul. 2014.

MANUAL DO PROGRAMA NACIONAL DE ALIMENTAÇÃO ESCOLAR - PNAE. Fundo Nacional de Desenvolvimento da Educação - FNDE. Disponível em: <http://www.fnde. gov.br/programas/alimentacao-escolar/agricultura-familiar>. Acesso em: 6 jul. 2014.

PREFEITURA MUNICIPAL DE CANOINHAS. Secretaria de Educação de Canoinhas, 2014. Disponível em: <http://pm.fecam.org.br/home/index.php?>. Acesso em: 6 jul. 2014.

PREFEITURA MUNICIPAL DE MAJOR VIEIRA. Secretaria de Educação de Major Vieira, 2014. Disponível em: <http://www.majorvieira.sc.gov.br>. Acesso em: 6 jul. 2014. 